Available online at GSC Online Press Directory

GSC Biological and Pharmaceutical Sciences

e-ISSN: 2581-3250, CODEN (USA): GBPSC2

Journal homepage: https://www.gsconlinepress.com/journals/gscbps

(RESEARCH ARTICLE)

\title{
Community pharmacists' response to acute back pain: A simulated patient study in western region, Saudi Arabia
}

\author{
Adil A. Mahmoud *, Omar A. Althobaiti, Abdulrahman E. Althobaiti, Anas O. Althomali, Osman M. Yossef \\ Department of Clinical Pharmacy, Faculty of Pharmacy, Al-Taif University, Saudi Arabia.
}

Publication history: Received on 23 January 2018; accepted on 07 February 2018

https://doi.org/10.30574/gscbps.2018.2.2.0008

\begin{abstract}
Objectives: To investigate response of the community pharmacists to acute back pain consultations by the patients, using doctor of pharmacy degree (Pharm D) final year students as simulated patients.

Method: The study was a cross-sectional study, conducted over a three months period from April 2016 to July 2016 in community pharmacy setting. The study was done at the western area in Saudi Arabia, at three cities: (Jeddah-MeccaTaif). Convenient sample of 300 pharmacies were chosen. The students appeared in the pharmacy as patients. A check list was filled immediately after the visit.

Results: Results of the study showed that most of pharmacies studied were chain pharmacies (67.3\%). The response of the pharmacists towards patients' counseling ranges from (6-55\%). The majority of the pharmacists did not ask about spreading of the pain (93\%), other disease (91\%), medications taken (90\%), intensity of pain (83.67\%), and duration (83\%). There was a low response of pharmacists towards self-care, except rarely, who gave advice for back exercise (6.667\%). About $98 \%$ and above, did not give information about expected drug problems. Referral was given mainly for numbness symptoms (10.67\%). Types of medications recommended were diclofenac sodium (44.67\%), muscle relaxants (28.67\%) and topical NSAIDS (25.33\%). About 70\%, of the pharmacists did not give advice spontaneously. Counseling time was less than one minute in $67.67 \%$ of the cases.
\end{abstract}

Conclusions: The response of community pharmacists, to acute back pain consultations was inadequate, which necessitates educational and training programs in minor disease treatment, and availability of national guidelines.

Keywords: Low back pain; Community pharmacy services; Simulated patients; Saudi Arabia

\section{Introduction}

Many studies, for different diseases, document inadequate patient counseling in community pharmacy [1-6]. The World Health Organization, in it's "Good Pharmacy Practice" document, encourages pharmacists to undergo more proactive functions towards patients [7]. Other organizations develop guidelines for pharmacist-conducted patient education and counseling [8].

Investigation of community pharmacists 'counseling through the use of simulated patients is one of procedures devised to reveal the gaps in this practice. The simulated patient might be a professional actor or other trained person. In study from Saudi Arabia, regarding counseling practices in community pharmacies at Riyadh city, the results showed that the majority of the simulated patients were given information only when they asked for it. Most of the pharmacists did not inquire about medication history and drug allergy. The only information provided by the majority of the pharmacists was information regarding the dose [9]. In study from Qatar, evaluating community pharmacy practice in acute 
gastroenteritis management, using simulated patient method; the findings indicate suboptimal dispensing practice, with limited information on drug use [10].

Acute low back pain is self-limiting, common disease. In US it accounts for the fifth most common reason patients see a medical practitioner and in UK 7 to $8 \%$ of all adult GP consultations are for low back pain [11]. A review of seven crosssectional studies, done at Saudi Arabia, investigating epidemiology of low back pain, revealed prevalence and pattern ranging from $53.2 \%$ to $79.17 \%$ [12]. Therefore, community pharmacies can give an additional setting for primary care for minor symptoms. The practice of dispensing Over- the- counter Medications (OTC), through responding to symptoms in community pharmacy, is one of the important roles of the pharmacists in improving patients 'self-care. Most community pharmacists, in developing countries are involved in responding to symptoms activities, but this practice is neglected by health authorities, underestimated and run without well- defined practice standards [13].

Acute low back pain is defined as pain present for less than 6 weeks [14]. In community pharmacy most low back pain conditions are expected to be mild, although a look for referral for high risk situations should always be attended for. Community pharmacies are considered as another gate, in addition to primary care clinics, for treatment for such a common ailment.

The American college of physicians and the American pain society [15] , recommends the following, when treating patients with back pain : a focused history and physical examination, no diagnostic tests for non-specific low back pain and this only required for severe conditions, advise and provide patients with evidence-based information , clinicians should consider the use of medications with proven benefits and safety, and for patients who do not improve with selfcare options, clinicians should consider the addition of non-pharmacologic therapy with proven benefit.

In Saudi Arabia an OTC directory was devised since 2000 [16], but it is obvious that this document is not activated in practice. Community pharmacies remain isolated from any joint programs with health authorities, as the case in most developing countries. There is paucity about studies from Saudi Arabia, investigating response of community pharmacists to acute back pain. The disease can affect a variety of populations: students, teachers, drivers and other workers.

This study aims to assess community pharmacists 'interaction with patients who suffer from acute back pain, in the western region of Saudi Arabia. The study was done in the main cities of this region: Jeddah, Mecca and Al-Taif.

\section{Methods}

The study was conducted over a three months period from April 2016 to July 2016 in community pharmacy setting. The study was done in the western area in Saudi Arabia, at three cities: (Jeddah-Mecca- Al Taif). The study population was all private community pharmacies in the three cities.

The study was a cross-sectional one. One of the trained students acted as a simulated patient suffering from low back pain and visited the pharmacy for advice and treatment. A convenient sample of 300 community pharmacies was chosen, 100 pharmacies from each city.

\subsection{Data collection tool}

A checklist was used, which should be completed by the student (simulated patient), immediately after the end of the visit to the pharmacy. This checklist was adapted from literature [17]. The checklist was piloted in 5 pharmacies.

The checklist was divided into two parts. Part one consisted of demographic and general information. Part two consisted of 34 items expected to be asked by the pharmacist. The main headings include: general questions to be asked by the pharmacist, advice for self-care, pharmacologic treatments, side effects and contraindications, referral suggestion, counseling duration and counseling spontaneity.

\subsection{Procedure}

Two students visited the community pharmacy, one of them acted as the patient, and the role of the second one was to double check any missing information from the actor student, and to observe any other points. The student who acted as the simulated patient was instructed not to give any information except if asked by the pharmacist. After the end of visit the two students, completed the checklist information outside the pharmacy immediately. 
This research was approved by the ethical committee of research in college of pharmacy, university of Al-Taif.

\subsection{Statistical Analysis}

The results were coded and entered in Excel and revised, then entered to SPSS version21. Descriptive statistics (frequencies/percentages) were used for general responses and One-Way Anova for comparison of the results of the three cities, location, pharmacy type and nationality.

\section{Results}

Demographic and general information are shown in table 1. The results of the study showed that most of the pharmacies studied were chain pharmacies (67.3\%). Most of the pharmacies were located in the main streets (77.3\%), and less in market area (3\%). We found that most of the pharmacies visited have low number of customers (ranging from 1-10). Most of the pharmacies had only one staff (85\%). The majority of the pharmacists were of Egyptian nationality ( $90.3 \%)$. There is no statistically significant difference between the location of the pharmacy (P0.087), pharmacy type (P0.085), city (P 0.375), and nationality (P 0.054) when compared with the responses of the pharmacists.

Table 1 Demographic and general information

\begin{tabular}{|c|c|c|c|}
\hline \multicolumn{2}{|c|}{ Demographics } & \multirow{2}{*}{$\begin{array}{c}\text { Number } \\
100\end{array}$} & \multirow{2}{*}{$\begin{array}{c}\text { Percentage (\%) } \\
33.3\end{array}$} \\
\hline City & Taif & & \\
\hline & Mecca & 100 & 33.3 \\
\hline & Jeddah & 100 & 33.3 \\
\hline \multirow[t]{2}{*}{ Pharmacy type } & Chain & 202 & 67.3 \\
\hline & Independent & 98 & 32.7 \\
\hline \multirow[t]{4}{*}{ Pharmacy location } & Private clinic & 25 & 8.3 \\
\hline & Street & 232 & 77.3 \\
\hline & Market area & 9 & 3.0 \\
\hline & Residential area & 34 & 11.3 \\
\hline \multirow[t]{11}{*}{ Number of visitors } & No visitor & 93 & 31.0 \\
\hline & One & 61 & 20.3 \\
\hline & Two & 71 & 23.7 \\
\hline & Three & 29 & 9.7 \\
\hline & Four & 20 & 6.7 \\
\hline & Five & 6 & 2.0 \\
\hline & Six & 6 & 2.0 \\
\hline & Seven & 6 & 2.0 \\
\hline & Eight & 2 & 0.7 \\
\hline & Nine & 4 & 1.3 \\
\hline & Ten & 2 & 0.7 \\
\hline \multirow[t]{3}{*}{ Number of staff } & One & 255 & 85.0 \\
\hline & Two & 42 & 14.0 \\
\hline & Three & 3 & 1.0 \\
\hline \multirow[t]{3}{*}{ Nationality } & Egyptian & 271 & 90.3 \\
\hline & Sudanese & 22 & 7.3 \\
\hline & Jordanian & 7 & 2.3 \\
\hline
\end{tabular}

Questions and advices given by the pharmacists are shown in Table 2. The response of the pharmacists, towards many patient counseling points was weak ranging from 6-28\%, with who have the back pain question being most frequently asked (55\%). Almost the majority of the pharmacists did not asked about spreading of the pain (93.67\%), any other disease $(91 \%)$, medications taken (90\%), intensity of pain $(83.67 \%)$, and duration (83\%). 
The study showed less response of the pharmacists towards self-care, except rarely, who gave advice for back exercise $(6.667 \%)$. Fewer advices were given for drug problems in general; some of these were directed towards gastrointestinal side effect of drugs (1.667\%), and allergy (1\%). The highest percentage for referral by the pharmacists was given to numbness (10.67\%).

Table 2 Questions and advices given by the pharmacist

\begin{tabular}{|c|c|c|c|}
\hline \multicolumn{2}{|r|}{ Questionnaire item } & \multirow{2}{*}{$\begin{array}{l}\begin{array}{c}\text { Percentage of } \\
\text { "Yes" (\%) }\end{array} \\
55.0\end{array}$} & \multirow{2}{*}{$\begin{array}{l}\begin{array}{c}\text { Percentage of } \\
\text { "No" (\%) }\end{array} \\
45.0\end{array}$} \\
\hline Questions asked & Who have the back pain & & \\
\hline $\begin{array}{l}\text { by } \\
\text { pharmacist }\end{array}$ & Age of the patient & 20.33 & 79.67 \\
\hline & When the pain occurs & 28.0 & 72.0 \\
\hline & Duration of the pain & 17.0 & 83.0 \\
\hline & Spreading of pain & 6.33 & 93.67 \\
\hline & Intensity of pain & 16.33 & 83.67 \\
\hline & Medications taken & 10.0 & 90.0 \\
\hline & Any other disease & 9.0 & 91.0 \\
\hline \multirow{5}{*}{$\begin{array}{l}\text { Advice for self- } \\
\text { care }\end{array}$} & Reassurance of favourable outcome & 0.0 & 100.0 \\
\hline & Advice to remain active & 0.33 & 99.67 \\
\hline & Give books, handouts and leaflets & 0.0 & 100.0 \\
\hline & Advice for superficial heat & 0.33 & 99.67 \\
\hline & Back exercise & 6.67 & 93.33 \\
\hline \multirow{5}{*}{$\begin{array}{l}\text { Advice for drug } \\
\text { problems }\end{array}$} & Gastrointestinal effects & 1.67 & 98.33 \\
\hline & Reno-vascular risk & 0.33 & 99.67 \\
\hline & Myocardial infarction & 0.33 & 99.67 \\
\hline & Allergy & 1.0 & 99.0 \\
\hline & Other side effects & 0.33 & 99.67 \\
\hline \multirow[t]{9}{*}{ Referral advice } & Infection & 0.0 & 100.0 \\
\hline & Radiating pain & 1.33 & 98.67 \\
\hline & Numbness & 10.67 & 89.33 \\
\hline & Worsening pain & 0.33 & 99.67 \\
\hline & Weight loss & 1.0 & 99.0 \\
\hline & Feeling unwell & 2.33 & 97.67 \\
\hline & Morning stiffness & 0.67 & 99.3 \\
\hline & Feeling unwell & 2.33 & 97.67 \\
\hline & Morning stiffness & 0.67 & 99.3 \\
\hline
\end{tabular}

The most recommended medications were: diclofenac sodium (44.67\%), muscle relaxants (28.67\%), and external nonsteroidal anti-inflammatory drugs -NSAIDs- (25.33\%). this is displayed in Table 3. 
Table 3 Pharmacologic treatment

\begin{tabular}{lll}
\hline Questionnaire item & $\begin{array}{c}\text { Percentage } \\
\text { of "Yes" } \\
\text { (\%) }\end{array}$ & $\begin{array}{c}\text { Percentage } \\
\text { of “No" } \\
\text { (\%) }\end{array}$ \\
\hline Paracetamol tablets & 10.67 & 89.33 \\
Ibuprofen tablets & 9.33 & 90.67 \\
Diclofenac sodium tablets & 44.67 & 55.33 \\
COX2 inhibitors tablets & 0.33 & 99.67 \\
Muscle relaxant tablets & 28.67 & 71.33 \\
External NSAIDs & 25.33 & 74.67 \\
Patches & 4.0 & 96.0 \\
\hline
\end{tabular}

Counseling duration and spontaneity are displayed in Table 4. Most of pharmacist took less time (less than 1 minute) in patient counseling (67.67\%), and (69.33\%) of pharmacists did not gave spontaneous advice.

Table 4 Counseling duration and spontaneity

\begin{tabular}{lll}
\hline \multicolumn{2}{c}{ Questionnaire Item } & Percentage (\%) \\
\hline Counseling duration & Less than 1 minute & 67.67 \\
& 1-5 minutes & 27.67 \\
& Above 5 minutes & 4.67 \\
\hline Counseling spontaneity & Spontaneous & 23.33 \\
& Upon request & 7.33 \\
& None & 69.33 \\
\hline
\end{tabular}

\section{Discussion}

The results of this study showed a clear suboptimal interaction of community pharmacists, in Saudi Arabia, with patients with acute back pain. This lack of adequate counseling seems to be a general trend with community pharmacists in developing countries [18-19].

Most of the pharmacies visited were chain pharmacies, and this shows the expected future role of this sector in Saudi Arabia, especially when constructing any patient-oriented practice programs. About half of the pharmacists asked about who is the patient, and less about other points, as occurrence of pain, age and duration. Counseling regarding spreading and intensity of pain was very poor. Regarding self-care advice, this found to be of rare occurrence, and when given it was for back exercise only. Almost there was no advice for the patients to stay active. This clearly emphasizes a lack of any previous training in patient counseling for minor diseases in general, and acute back pain in particular. Although pharmacies were not crowded, as most pharmacies have only one to two patients during the time of simulated patient 'visit, still pharmacists were not able to get this chance for proper counseling. Most pharmacists were not inclined to give any information before the cost of the medication was paid.

Diclofenac sodium tablets was the main drug recommended, followed by muscle relaxants and superficial medications. Generally no importance was given towards side effects and risks of medication information. Referral practice is very weak, and this may be due to lack of any organized system of referral.

These results are similar to two studies from Australia. The findings of the first study, which used a cross-sectional survey among Australian chiropractors, showed that there was less advice for patients to stay active [20]. In a recent 
observational study, among Australian community pharmacists [17], there was inadequate provision of reassurance of favorable outcomes and advice to stay active. In this study diclofenac sodium was the most used medication. Acetaminophen, as an additional drug, was recommended in only $3 \%$ of visits, while in our study it was supplied, as a single drug, in about $10 \%$ of the visits. The findings of a simulated patient study from Malaysia [21], among community pharmacists, obtained similar results to our study. The general results in this study showed a suboptimal response of community pharmacists to back pain treatment. Only five counseling elements, of 13 recommended were addressed. The authors reported that when medication was requested by name, this was probably one of the reasons of less counseling. The most recommended medication was oral diclofenac sodium, followed by COX-2 inhibitors, and topical non-steroidal anti-inflammatory drugs (NSAIDs). Compared to the current study diclofenac was mostly used, followed by, muscle relaxants, topical NSAIDs, and COX2 inhibitors were almost rarely recommended. The most frequent counseling point addressed, in this study, was the route of administration, followed by frequency and dose. In our study the same was addressed. Regarding questions commonly asked by the pharmacists, this study is in contrast to the present study, in that the most asked question was about the medical history, followed by patient identity and age. In our study the question asked frequently was about patient identity, followed by time of occurrence of the pain, and age. Both studies generally arrive at correct counseling information although identity of the patient should be established before any treatment. Most of the consultation time, in this study, took less than two minutes or $2-5$ minutes with a median time of 1 minute. In our study most of the consultations took less than one minute, followed by between 1-5 minutes. This is considered a very critically low time, to gain information about the patient. Spontaneous counseling in the current study was very low, as most of the pharmacists responded only when the patients asked.

In most of the developing countries community pharmacy is always isolated from governmental healthcare institutions. This could be solved by integration in joined national programs. Minor diseases are a fertile area to start the change. The role of the community pharmacists in this area will decrease the load in primary health clinics and hospitals. The uniqueness of the community pharmacy, as an easy accessed health setting should not be underestimated. Guidelines and proper training courses should be constructed .Above all; a link between ministry of health and this sector should be developed. As starting point the presence of the high number of chain pharmacies, can give a proper organized channel of cooperation though contracts, with health authorities, in minor diseases programs. Many developed countries as: UK, USA, and Canada [22-24], have initiated successful programs with proper contracts with authorities.

The future of provision of triage service in community pharmacy was investigated in a review of thirty seven studies [25]. The authors commented that in all these studies pharmacists were found to make appropriate differential diagnosis, but those who do not use guidelines/protocols did not ask sufficient questions. They concluded that community pharmacy triage service is feasible and appropriate, and has the potential to reduce burden on other healthcare services, but a worry about the consistency and funding of the service remains there.

The study has some limitations. A convenient sample was used. The study was not audiotaped, as some problems with voice recording was encountered, when piloted .One scenario was used in which the simulated patient asked for treatment of acute back pain. The other expected scenario of asking about specific medication was not used.

The implication of these results to practice is summarized in the following: community pharmacists should have access to international guidelines for treatment of minor diseases, and they should be linked to training courses, to be given by pharmacy authorities. National guidelines should be made. Future studies should investigate barriers for professional practice in community pharmacies.

This study, according to our literature search, is the first simulated patient study investigating acute back pain, among community pharmacists, in Saudi Arabia.

\section{Conclusion}

There is inadequate counseling, for acute back pain, in Saudi community pharmacies in the western region. This should be augmented by the use of guidelines or protocols, and training. To improve pharmacy practice in this area a sort of contracts with community pharmacies and health authorities, to offer minor diseases services, should be devised. 


\section{Compliance with ethical standards}

\section{Acknowledgments}

The authors acknowledge the contribution of all the pharmacy managers in the private pharmacies for giving the chance for undergoing this research.

\section{Disclosure of conflict of interest}

The authors declare no conflict of interest.

\section{References}

[1] Fortoutan N and Dabaghazadeh F. (2016). Evaluating the practice of Iranian community pharmacists regarding oral contraceptive pills using simulated patients. Pharmacy practice, 14(4), 745.

[2] Al-Qahtani IS, Almoteb TM and Al-Warafi YM. (2015). Competency of metered-dose inhaler use among Saudi community pharmacists: A Simulation method study. Research and Reviews: Journal of Pharmacy and Pharmaceutical Sciences, 4(2), 27-31.

[3] Sancar M, Tezan E, Okuyan B and Izzettin FV. (2015). Assessement of the attitude of community pharmacists and pharmacy technicians towards diarrhea: A simulated patient study in Turkey. Tropical Journal of Pharmaceutical Research, 14(8), 1509-1515.

[4] Obreli-Neto PR, Pereira LR, Guidoni CM, de Oliveira Baldoni A, Marusic S, de Lyra-Júnior DP, de Almeida KL, Pazete AC, do Nascimento JD, Kos M and Girotto E (2013). Use of simulated patients to evaluate combined oral contraceptive dispensing practices of community pharmacists. Plos One, 8(12), e79875.

[5] Hussain A, Ibrahim M, Malik M. (2013). Assessement of disease management of insomnia at community pharmacies through simulated visits in Pakistan. Pharmacy Practice, 11(4), 179-184.

[6] Hussain A, Ibrahim M, Malik M. (2012). Assessement of disease management of acute respiratory tract infection at community pharmacies through simulated visits in Pakistan. Latin American Journal of Pharmacy, 31(10), 1435-1440.

[7] World health organization (1996). Good Pharmacy Practice (GPP): In Community and Hospital pharmacy Settings. WHO/PHJARM/DAP/96.1.

[8] American Society of Health-System Pharmacists (1997). Medication therapy and patient care: Organization and delivery of services-guidelines, 280-282.

[9] Alaqeel S and Abanmy NO. (2015).Counselling practices in community pharmacies in Riyadh, Saudi Arabia: a cross e-sectional study. BMC Health Services Research, 15, 557.

[10] Ibrahim MI, Palaian S, Al-Sulaiti F and El-Shami S. (2016). Evaluating community pharmacy practice in Qatar using simulated patient method: acute gastroenteritis management. Pharmacy Practice, 14(4), 800.

[11] Paul R. (2009). Musculoskeletal conditions, Community Pharmacy: symptoms, diagnosis and treatment; $2^{\text {nd }}$ edition, Churchill Livingstone, Elsevier. London, UK, 246.

[12] Awaji MA. (2016). Epidemiology of low back pain in Saudi Arabia. Journal of Advances in Medical and Pharmaceutical Sciences, 6(4), 1-9.

[13] Mohamed SS, Mahmoud AA and Ali AA. (2014). The role of Sudanese community pharmacists in patients'selfcare. International Journal of Clinical Pharmacy, 36, 412-419.

[14] Casazza BA. (2012). Diagnosis and treatment of acute low back pain. American Family Physician, 85(4), 343-350.

[15] Chou R, Qaseem A, Snow V, Casey D, Cross T, Shekelle P and Owens DK. (2007). Diagnosis and treatment of low back pain: A joint clinical practice guidelines from the American college of physician and the American pain society. Annals of Internal Medicine, 147(7), 478-491.

[16] Al-Rukban MO and Khalil MA. (2012). Adherence to OTC directory--the perception of community pharmacists in Saudi Arabia. Journal of Ayub Medical College Abbottabad, 24(3-4), 43-46.

[17] Shaheed CA, McFarlane B, Maher CG, Williams KA, Bergin J, Matthews A and Mclachlan A. (2016).Investigating the primary care management of low back pain: A simulated patient study. The Journal of Pain, 17(1), 27-35. 
[18] Hussain A and Ibrahim MIM. (2012). Management of diarrhea cases by community pharmacies in 3 cities of Pakistan. Eastern Mediteranian Health Journal, 18, 635-640.

[19] Santos AP, Mesquita AR, Oliveira KS and Lyra DP Jr. (2013). Assessment of community pharmacists' counseling skills on headache management by using the simulated patient approach: a pilot study. Pharmacy Practice, 11, 37.

[20] Walker BF, French SD, Page MJ, O'Connor DA, Mckenize JE, Beringer K, Murphy K, Keatingn JL, Michie S, Francis JJ and Green SE. (2011). Management of people with acute low-back pain: a survey of Australian chiropactors. Chiropractic and Manual Therapies, 19, 29.

[21] Chua SS, Ramachandran CD and Paraidathathu TT. (2006). Response of community pharmacists to the presentation of back pain. A simulated patient study. International Journal of Pharmacy Practice, 14(3), 171-178.

[22] NHS Community Pharmacy Services-a summary (2015). Available: https://www.psnc.org.uk/wpcontent/upload/2015/06/CPCF-summary-june-2005.pdf, last accessed on 15/8/2016.

[23] American Pharmacists Association and National Association of Chain Drug Stores Foundation. (2005). Medication Therapy Management in community pharmacy practice: core elements of an MTM service (version 1.0). Journal of the American Pharmacists Association, 45(5), 573.

[24] Meds Check: Resources for pharmacists (2007). Available: https://www.health.gov.on.ca/en/pro/programs/drugs/medscheck original apx., last accessed on 25/10/2016.

[25] Curley LE, Moody J, Gobarani R, Aspden T, Jensen M, McDonald M, Show J and Sheridan J. (2016). Is there potential for the future provision of triage services in community pharmacy? Journal of Pharmaceutical Policy and Practice, 9, 29.

\section{How to cite this article}

Adil AM, Omar AA, Abdulrahman EA, Anas OA, Osman MY. (2018). Community pharmacists' response to acute back pain: A simulated patient study in western region, Saudi Arabia. GSC Biological and Pharmaceutical Sciences, 2(2), 25-32. 